\title{
A Study of Short-term Partial Discharge Aging of Polypropylene Film
}

\author{
V. Krishnan \\ and R. S. Nema \\ Department of HV Engineering, \\ Indian Institute of Science, Bangalore, INDIA.
}

\begin{abstract}
Polypropylene film has been subjected to surface discharges of known initial maximum discharge magnitude for different periods of time (2 to $12 \mathrm{~h}$ ) at sub-atmospheric pressures ranging from 10 to $66.50 \mathrm{kPa}$, using uniform field electrodes with ac voltage stress of $625 \mathrm{kV} / \mathrm{cm}$. By measuring the residual breakdown voltage of the aged samples, a degradation rate curve is obtained and an estimate of the life of the films under experimental conditions is attempted. These estimates are compared with results from life tests where the samples are stressed to failure. The estimates are extended to normal service conditions. The erosion of the films is studied from the microphotographs of the aged samples.
\end{abstract}

\section{INTRODUCTION}

$\mathrm{P}$ OLYPROPYLENE (PP) film is widely used as a dielectric in HV capacitors. The design stress is of the order of $600 \mathrm{kV} / \mathrm{cm}$. At this stress, one of the major causes of capacitor failure is partial discharge (PD) $[1,2]$. In these capacitors, the outer turns may not be wound as tight as the inner turns and as a result gaseous gaps between the film can exist and hence PD are more probable in the outer turns [3]. It is also possible that these small airgaps may be at different sub-atmospheric pressures due to the process of vacuum impregnation [4]. Although it is probable that, with time, the void pressure will equilibrate with that of the surrounding ambient medium due to diffusion processes, the time taken for these processes is long. It is, therefore, essential to study PD under such conditions. Studies have been made earlier to describe a number of factors affecting the breakdown of dielectrics with PD and to study the variation of ac dielectric strength with time of voltage application for a variety of dielectrics [5,
6]. Methods have also been devised to measure PD in capacitors and permissible PD levels are specified $[7,8]$. There is at present no traceable method of estimating the life of the capacitor insulation under the influence of PD. Moreover, it is not yet established which of the discharge parameters (maximum initial discharge magnitude or total discharge magnitude/s or discharge energy) can be attributed to cause real damage leading to the failure of the insulation. No definite correlation thus exists so far between any of the discharge quantities and the life of a capacitor.

In the work reported here, an attempt has been made to study the PD degradation of PP films by conducting short-term aging tests under subatmospheric pressures. A degradation rate curve is obtained and an estimation of the life of the films under experimental conditions is attempted by measuring the residual breakdown voltage of the aged samples. 


\section{EXPERIMENTAL TECHNIQUE}

The following experiments were conducted

1. Short-term aging of PP films (Uniphane ${ }^{\mathrm{TM}}$ M. P. United PP Ltd., Bhopal, India; thickness $19.3 \mu \mathrm{m}, \varepsilon_{r}=2.2$, $\tan \delta=0.0004$ at $50 \mathrm{~Hz}$ ) with initial maximum discharge magnitude $Q_{m}$ ranging from 3000 to $6000 \mathrm{pC}$. The experiments were conducted at subatmospheric pressures of $10.00,21.95,33.25$ and $66.50 \mathrm{kPa}$.

2. Measurement of electric strength over the aged area of the PP film samples.

3. Life tests where the samples were aged up to failure.

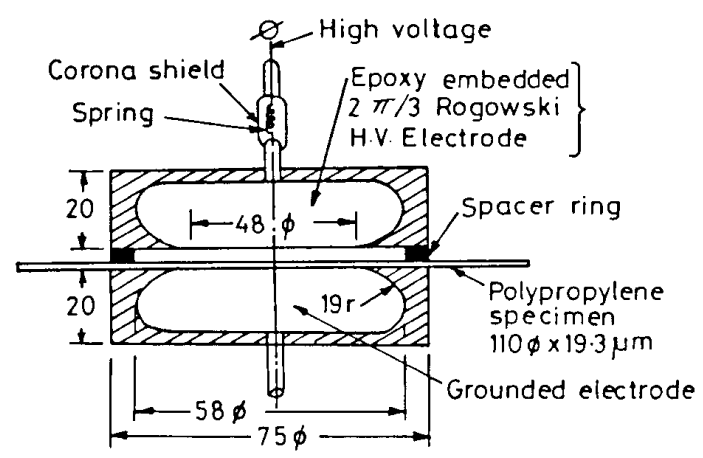

Figure 1.

Arrangement for surface discharge aging, (all dimensions are in $\mathrm{mm}$ ).

The arrangement used for aging the samples is shown in Figure 1. The samples used were $11 \mathrm{~cm}$ diameter PP films. The electrodes used were $2 \pi / 3$ Rogowski profile uniform-field brass electrodes of $5.8 \mathrm{~cm}$ overall diameter and $1.9 \mathrm{~cm}$ radius of curvature embedded in epoxy (to form $7.5 \mathrm{~cm}$ overall diameter and $2 \mathrm{~cm}$ overall thickness) except for the flat portion of the electrode surface (exposed effective diameter of the electrode being $4.8 \mathrm{~cm}$ ). The sample was placed on the bottom grounded electrode. The top electrode was separated by an airgap with the help of a bakelite spacer ring $(7.5 \mathrm{~cm}$ outer-diameter, $6.5 \mathrm{~cm}$ inner-diameter and a $0.5 \mathrm{~cm}$ opening for ventilation). An initial estimate of the thickness of the spacer ring required at a given pressure to produce an inception stress of $500 \mathrm{kV} / \mathrm{cm}$ in the sample was obtained from the Paschen curve for dry air. The thicknesses of the spacer rings used were $0.32,0.15,0.10,0.05 \mathrm{~cm}$ corresponding to the pressures of $10.00,21.95,33.25$ and $66.50 \mathrm{kPa}$, respectively.

A mild-steel cylindrical chamber of $45 \mathrm{~cm}$ diameter and $40 \mathrm{~cm}$ depth accommodating three such electrode systems was used to carry out simultaneous aging of three samples. The top of the chamber was covered by a $1.25 \mathrm{~cm}$ thick PMMA (polymethyl methacrylate), easily removable lid to facilitate visual observations of the inner system. Three cast-resin bushings were fitted to the lid for applying $50 \mathrm{~Hz} \mathrm{HV}$ obtained from a $12 \mathrm{kV}, 3.5 \mathrm{kVA}$ PDfree transformer. Before starting the experiments, the chamber was evacuated using a double-stage rotary pump and fresh air, dried over dehydrating agents, was admitted to yield the required pressure. A period of $30 \mathrm{~min}$ was provided before commencement of the experiment, for stabilization of pressure.

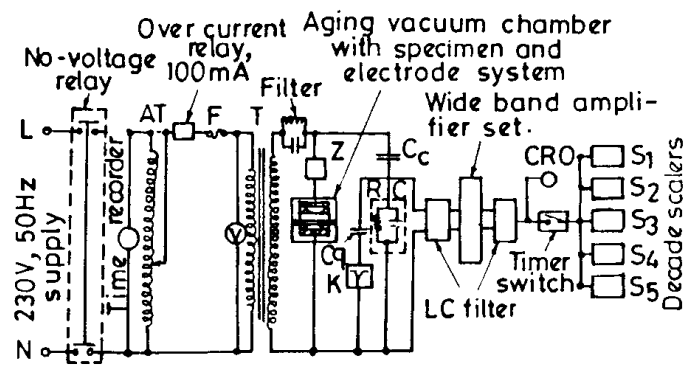

Figure 2. Schematic diagram of test circuit.

The schematic diagram of the test circuit is shown in Figure 2. A matching unit consisting of a $R C$ circuit $(R=27 \Omega, C=0.1 \mu \mathrm{F})$, a coupling capacitor $(400 \mathrm{pF}$, manufactured by Miles HiVolt Ltd., England), Philips wideband amplifier GM 6012 (bandwidth $2 \mathrm{~Hz}$ to $1 \mathrm{MHz}$, two amplifiers in cascade to increase the gain), powerfrequency filters at the input and output stage of the amplifier set, cathode ray oscilloscope (CRO), and other necessary instruments were used for the detection and measurement of discharge pulses. Calibration was performed by introducing pulses of a known magnitude from a Bonar $751 \mathrm{R}$ PD calibrator, across the $R C$ circuit, through a known capacitor and measuring the response on the CRO. The minimum PD detected was $25 \mathrm{pC}$. This sensitivity was sufficient for the experiments conducted. The resolution was 250 pulses per quadrant. Five decade scalers were used for pulse height analysis.

The PD inception stresses were around $500 \mathrm{kV} / \mathrm{cm}$ $( \pm 5 \%)$ at all pressures and the applied voltage was increased further by $1.25 \times$ so that there was no extinction of discharges during the aging period. The aging stress was thus $625 \mathrm{kV} / \mathrm{cm}$. The initial maximum discharge magnitude $\left(Q_{m}\right)$ at the aging voltage was controlled at a desired value (3000 to $6000 \mathrm{pC}$ ) by changing the impedance $Z$ (non-inductive) in series with the samples without affecting the overall sensitivity of detection. Basically this impedance controls the operating point of the discharge current on the $I-V$ characteristic in the subnormal region of the discharge occurring in a void [9]. The samples 
were aged for different times ranging from 2 to $12 \mathrm{~h}$. In case of failure of a sample before the specified period, it was disconnected from the supply, and the time of aging was taken to be the time to failure. In order to obtain the pulse distribution for each $Q_{m}$, the PD inception and extinction voltages, maximum discharge magnitude, the number of pulses and their distribution were measured at regular intervals on one sample in each case for a period of $8 \mathrm{~h}$ or to the time of failure, whichever was earlier.

The electrode system measuring the electric strength of the aged samples, consists of a cylindrical brass rod (0.625 $\mathrm{cm}$ diameter with rounded edges, weight $150 \mathrm{~g}$ ) as the HV electrode and a flat circular brass plate $(14 \mathrm{~cm}$ diameter, 1 $\mathrm{cm}$ thick) as the ground electrode. The dielectric strength measurements of the aged area of the sample were carried out in a Perspex ${ }^{\text {TM }}$ container filled with good quality dry transformer oil, so that flashover along the surface of the sample was avoided. The applied voltage $(50 \mathrm{~Hz})$ was increased from zero to breakdown in steps of $125 \mathrm{~V}$, every $5 \mathrm{~s}$. It was possible to carry out the measurement of dielectric strength at 20 sites over the aged area of each sample. The residual breakdown voltage (RBDV) is taken as the median of the 20 breakdown voltages so obtained. The ratio of the 'RBDV to the thickness of the sample is named RES (residual electric strength) and the ratio of RES of the aged sample to the breakdown strength of the fresh sample is named RRES (relative residual electric strength).

\section{RESULTS}

$\mathrm{T}$ ABLE 1 shows the values of RRES and the coeffcient of dispersion of breakdown voltages at the experimental pressure of $33.25 \mathrm{kPa}$. It is observed that the coefficient of dispersion, caused mainly by material and electrode pitting, is within $40 \%$ in most of the cases, which indicates that the aging of the samples had been reasonably uniform. At $10,21.95$ and $66.50 \mathrm{kPa}$ similar observations have been obtained but are not shown here due to limitations of space.

\subsection{RELATIONSHIP BETWEEN RRES AND AGING TIME}

The plot of the RRES value for the samples aged under the same initial maximum discharge magnitude $Q_{m}$ against the aging time is named the RRES- $t$ characteristic.

Simoni [10] has devised a short-term aging test in which the samples are aged at a constant stress for different

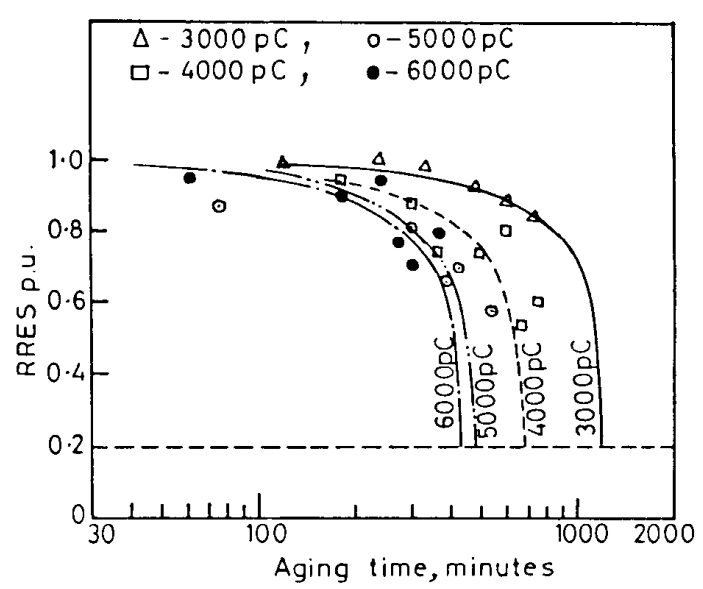

Figure 3.

RRES- $t$ characteristic-fitting of Equation (1), pressure: $33.25 \mathrm{kPa}$.

periods. The RBDV of the aged samples is taken as a measure of the degradation of the insulation. Simoni has proposed the empirical equation

$$
1-\left[\frac{g_{f}}{g_{f 0}}\right]^{n+1}=\left[\frac{g}{g_{f 0}}\right]^{n}\left[\frac{t}{t_{f 0}}\right](n+1)
$$

where $g_{f}$ is the breakdown strength (BDS) of the aged samples, $g_{f 0}$ is the BDS of the fresh sample, $g$ is the aging stress, $t$ is the aging time, $t_{f o}$ is the time to breakdown for the fresh sample in the progressive stress test, and $n$ is the voltage endurance coefficient. An attempt is made here to fit the above equation to the present RRES- $t$ data on the basis that PD give rise to certain induced electrical stress over and above the applied stress. Using iterative techniques, the value of $n$ for each $Q_{m}$ is obtained. Figure 3 typically shows the experimental points and the fitted curves at $33.25 \mathrm{kPa}$. The experimental points and the fitted curves at $66.50 \mathrm{kPa}$ have been shown in an earlier paper by the same authors [11]. The life corresponding to a particular $Q_{m}$ is taken as the time when RRES reaches a value equal to the ratio of the aging stress to the breakdown strength of the fresh samples which is 0.2 in these experiments. In other words, with aging, the residual electric strength equals the aging stress for the estimation of life.

\subsection{VERIFICATION OF THE EXTRAPOLATED LIFE TIMES}

In some cases, life tests have been conducted where the samples were stressed to failure. Nine samples were tested for each $Q_{m}$ and the most probable time to failure is obtained from the Weibull distribution. Figure 4 shows 
Table 1 .
Variation of RES and RRES with ageing time for various initial maximum discharge magnitudes.

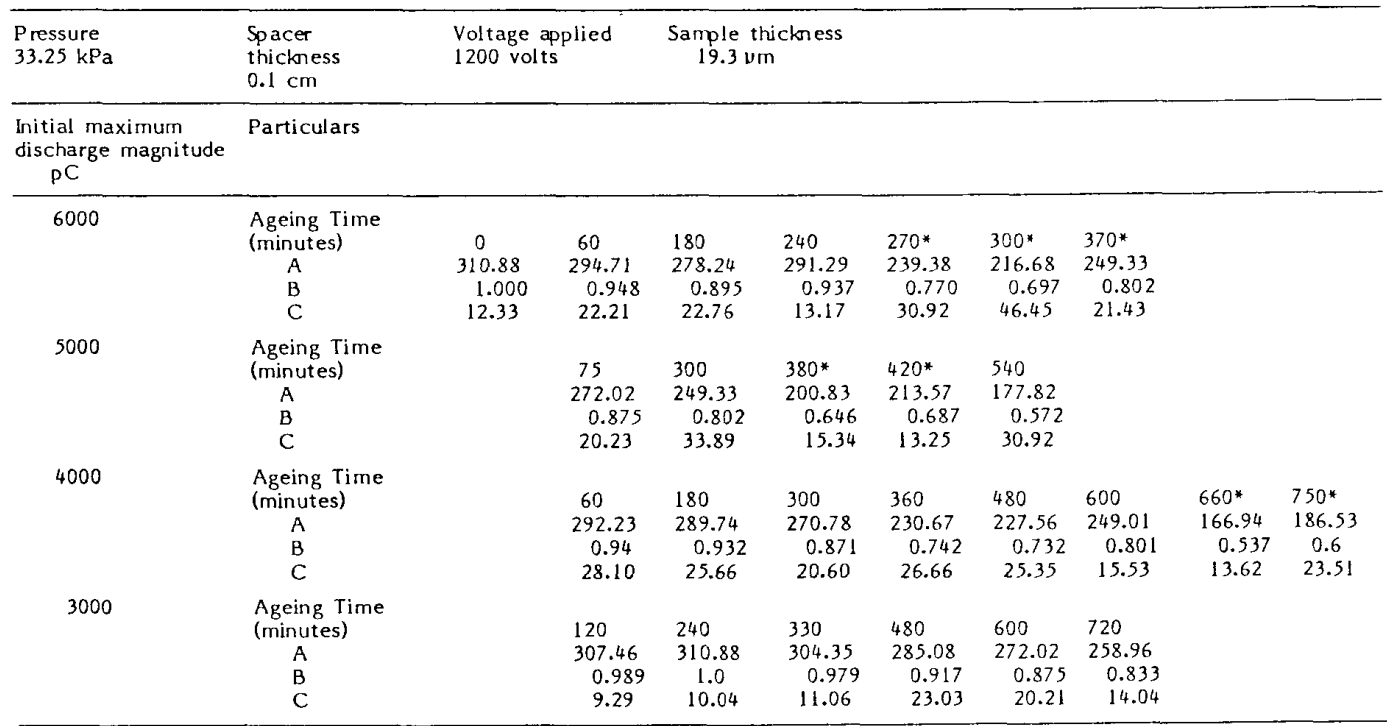

A - Residual electric strength (RES), Median Value, $v / \mu m$ $B$ - Relative residual electric strength (RRES) (p.u. value)

\section{DISCUSSION}

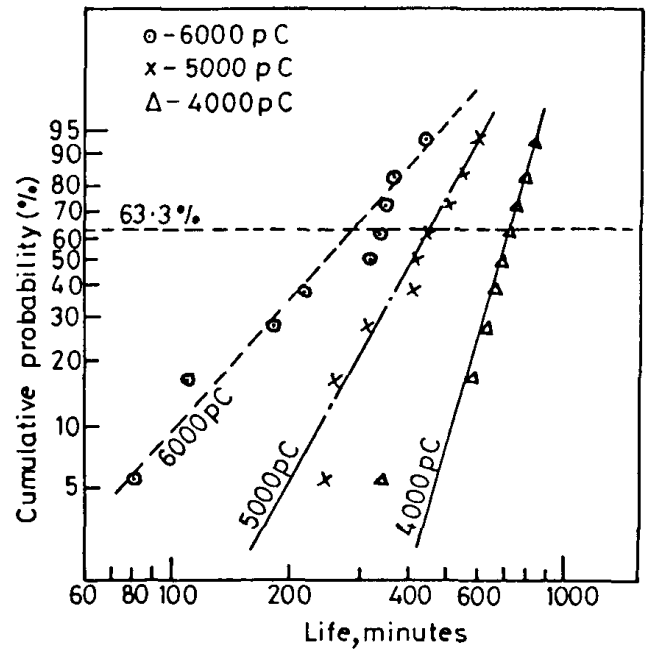

Figure 4.

Weibull plots of failure times, pressure: $33.25 \mathrm{kPa}$.

Table 2 shows the values of the voltage endurance coefficient $n$, the extrapolated life times from Equation (1) and lifetimes obtained from life tests for various initial maximum discharge magnitudes and pressures. It also shows the average of the overvoltages applied during the aging tests.
Table 2 reveals the following.

1. The extrapolated lifetimes agree reasonably well with the lifetimes obtained from life tests. Thus the method of short-term aging developed here seems to be well suited for PD aging of thin insulating films.

2. At all pressures, the extrapolated lifetimes vary consistently with the initial maximum discharge magnitude i.e. as $Q_{m}$ increases lifetime decreases.

3. For a given $Q_{m}$ at different pressures, the extrapolated lifetimes seem to depend on the overvoltages applied. In general, as overvoltage increases, lifetimes seem to decrease. It can be said that the extrapolated lifetimes for a given $Q_{m}$ seem to be independent of pressure and the observed changes in the lifetimes may be attributed to the changes in the overvoltages applied during the experiments.

\subsection{VARIATION OF $n$ WITH $Q_{m}$}

Augood [12], in his review on dielectric aging, has referred to the results of various workers and shows that for the same voltage stress applied $n$, the voltage endurance 
Table 2.

Variation of $n$, extrapolated lives and mean time to failure (from life tests) with initial maximum discharge magnitude $\left(Q_{m}\right)$ and pressure.

\begin{tabular}{|c|c|c|c|c|c|c|}
\hline \multicolumn{2}{|c|}{$\begin{array}{l}\text { Initial max } \\
\text { discharge } \\
\text { magnitude } \\
\text { pC }\end{array}$} & $\begin{array}{l}\text { Pressure } \\
\mathrm{kPa}\end{array}$ & $\begin{array}{r}66.50 \\
3.775\end{array}$ & $\frac{33.25}{3.899}$ & $\frac{21.95}{3.833}$ & $\frac{10.00}{3.544}$ \\
\hline 6000 & $\begin{array}{l}A \\
B \\
C \\
D\end{array}$ & & $\begin{array}{l}3.775 \\
370 \\
356 \\
1.195\end{array}$ & $\begin{array}{l}3.899 \\
440 \\
293 \\
1.247\end{array}$ & $\begin{array}{l}3.833 \\
395 \\
230 \\
1.256\end{array}$ & $\begin{array}{l}3.544 \\
264 \\
105 \\
1.257\end{array}$ \\
\hline 5000 & $\begin{array}{l}\mathrm{A} \\
\mathrm{B} \\
\mathrm{C} \\
\mathrm{D}\end{array}$ & & $\begin{array}{l}4.044 \\
530 \\
457 \\
1.155\end{array}$ & $\begin{array}{l}3.953 \\
470 \\
458 \\
1.287\end{array}$ & $\begin{array}{l}3.989 \\
492 \\
452 \\
1.214\end{array}$ & $\begin{array}{l}4.017 \\
512 \\
360 \\
1.233\end{array}$ \\
\hline 4000 & $\begin{array}{l}\text { A } \\
B \\
C \\
D\end{array}$ & & $\begin{array}{l}4.237 \\
700 \\
638 \\
1.203\end{array}$ & $\begin{array}{l}4.202 \\
660 \\
713 \\
1.232\end{array}$ & $\begin{array}{l}4.167 \\
633 \\
712 \\
1.203\end{array}$ & $\begin{array}{l}4.186 \\
650 \\
540 \\
1.185\end{array}$ \\
\hline 3000 & $\begin{array}{l}A \\
B \\
C \\
D\end{array}$ & & $\begin{array}{c}4.692 \\
1350 \\
- \\
1.228\end{array}$ & $\begin{array}{c}4.605 \\
1180 \\
- \\
1.244\end{array}$ & $\begin{array}{c}4.762 \\
1479 \\
- \\
1.217\end{array}$ & $\begin{array}{c}4.540 \\
1076 \\
-\quad 1.163\end{array}$ \\
\hline 10 & $\begin{array}{l}\text { A } \\
\text { [extr } \\
\text { valu } \\
n=\end{array}$ & $\begin{array}{l}\text { apolated } \\
\text { from equ } \\
+b \ln (1 / Q\end{array}$ & 12.02 & 10.65 & 12.25 & 12.28 \\
\hline
\end{tabular}

A - Voltage endurance coefficient $n$

B - Extrapolated life from Eq. (1), (in minutes)

C - Mean time to failure from life tests (in minutes)

D - Average of avervoltages applied

coefficient varies with the operating temperature $T$ most probably in the form $n=A+B / T$, where $A$ and $B$ are constants. In the present experiments $n$ varies with $Q_{m}$ for the same applied electrical stress. An attempt has been made to fit an equation of the form

$$
n=a+b \ln \left(\frac{1}{Q_{m}}\right)
$$

to the values of $n$ and $Q_{m}$ at each pressure.

Table 2 shows the extrapolated value of $n$ at different pressures corresponding to permissible discharge magnitude of $10 \mathrm{pC}$. The choice of $10 \mathrm{pC}$ as the permissible discharge magnitude agrees well with the results of Curtis et al. [2] and the observations of Cesari et al. [13].

\subsection{VARIATION OF $n$ WITH PRESSURE}

It is observed from Table 2 that the $n$ values for a given $Q_{m}$ do not vary appreciably with pressure. The small variations observed can be attributed to the variations in the overvoltages used. Hence the average value of $n$ for each $Q_{n}$ is calculated and presented in Table 3 . Substituting these average values of $n$ in Equation (2), the value of $n$ at $10 \mathrm{pC}$ as the permissible discharge magnitude is estimated to be 11.8. This is well within the range of the values of $n$ (ranging from 5 to 20 depending on the voltage stress applied) reported by Pattini et al. [14].

Table 3. Average value of $n$ and life times

\begin{tabular}{|lcc|}
\hline \hline $\begin{array}{l}Q_{m} \\
\text { pC }\end{array}$ & $\begin{array}{c}\text { Average value } \\
\text { of } n\end{array}$ & $\begin{array}{c}\text { Extrapolated life } \\
\text { time from (1) } \\
\text { min }\end{array}$ \\
\hline 6000 & 3.8 & 357 \\
5000 & 4.0 & 500 \\
4000 & 4.2 & 661 \\
3000 & 4.7 & 1257 \\
\hline
\end{tabular}

\subsection{ESTIMATION OF LIFE TIMES AT LOW VALUES OF $Q_{m}$}

The average value of $n$ for each $Q_{m}$ is used in Equation (1) to estimate the lifetime which can be considered to be the average lifetime for each $Q_{m}$, taking all the experimental pressures into account. These life times are 
presented in Table 3. An attempt is made to fit to the present data an equation of the form

$$
L=A Q_{m}^{B}
$$

where $L$ is the average estimated life time, $Q_{m}$ the initial maximum discharge magnitude and $A$ and $B$ are constants.

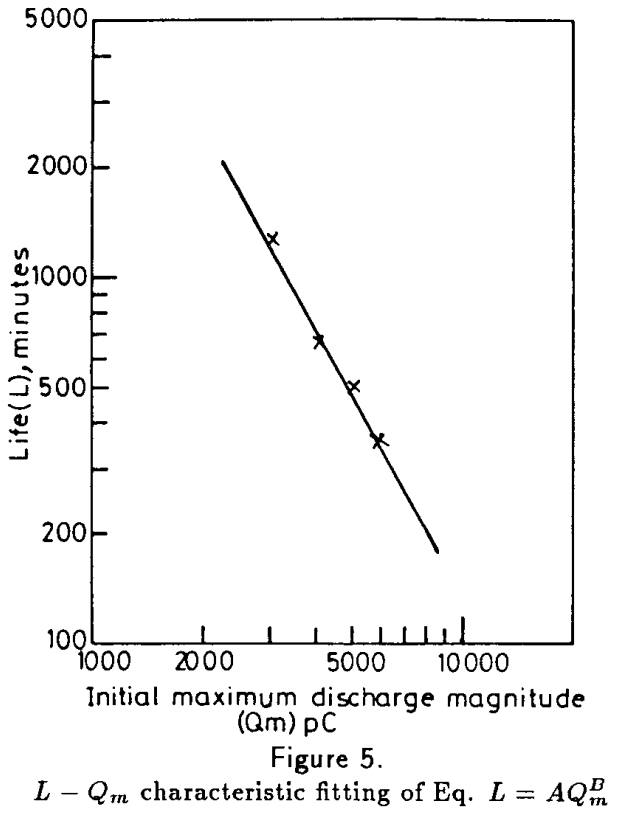

Figure 5 shows the fitted curve. For a permissible discharge magnitude of $10 \mathrm{pC}$, Equation (3) yields a life of about $57 \mathrm{yr}$. This agrees reasonably well with the life estimate of folded-foil PP film capacitors by Umemura et al. [1] which is more than $30 \mathrm{yr}$.

\subsection{CORRELATION BETWEEN TOTAL DISCHARGE MAGNITUDE/S AND EXTRAPOLATED LIFE TIMES}

For each $Q_{m}$, on one sample, the PD inception and extinction voltages, the maximum discharge magnitude, the number of pulses and their distribution were measured at regular intervals for a period of $8 \mathrm{~h}$ or to the failure of the sample whichever was earlier. From these data, the total discharge magnitude/s $\left(Q_{T}\right)$ is calculated and averaged over the test period. This $Q_{T}$ is plotted against the extrapolated lifetimes as shown in Figure 6. It is observed that the points lie around a straight line and hence a straight line has been fitted to the points. The fact that $Q_{T}$ shows a good correlation with the extrapolated lifetimes implies that $Q_{T}$ is also an important factor in the

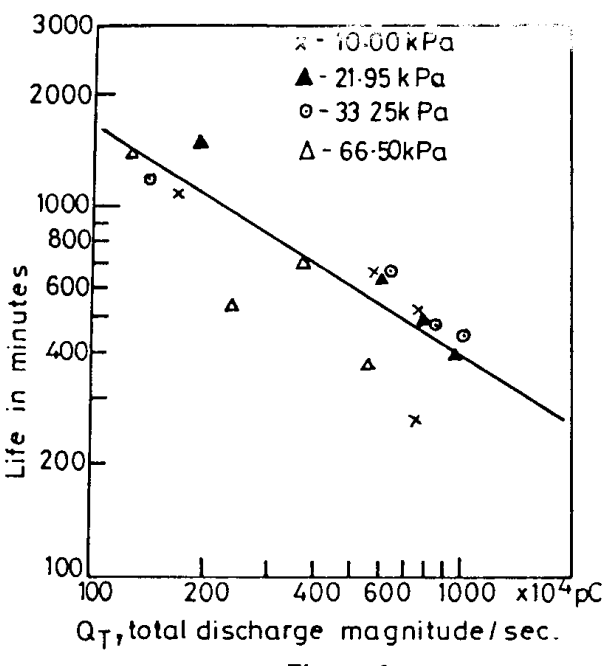

Figure 6 .

Correlation between $Q_{T}$ and estimated life.

$\mathrm{PD}$ degradation of $\mathrm{PP}$ films, in addition to the normally specified maximum discharge magnitude.

\subsection{SURFACE DEGRADATION OF THE AGED SAMPLE}

Due to surface discharges pits are formed on the surface of the PP film and hence there is a reduction in the thickness of the film. To obtain an idea of the dimensions of the pits formed, microphotographs of the aged samples were taken using a Carl Zeiss microscope (magnification $250 \times$ ). Each sample was photographed at three sites, selected randomly over the aged surface. The diameter of the largest pit was measured from the photographs. Figure 7 shows a typical microphotograph.

Figure 8 shows the plot of pit diameter with aging time at different pressures and initial maximum discharge magnitudes. It is observed that the pit diameter in general increases with aging time, showing that as aging progresses, erosion of the film increases. It is also observed that the pit diameter increases with increase in initial maximum discharge magnitude.

Since it has been found that there is a reduction in the breakdown voltage of the aged samples, an attempt is made to relate the erosion of the film with the reduction in the breakdown voltage. The breakdown voltage of fresh PP films of various thicknesses were measured, as shown by the curve in Figure 9. Assuming hemispherical pits to be formed on the surface of the film due to discharges, if the radius of the largest pit is $r$, and the initial 


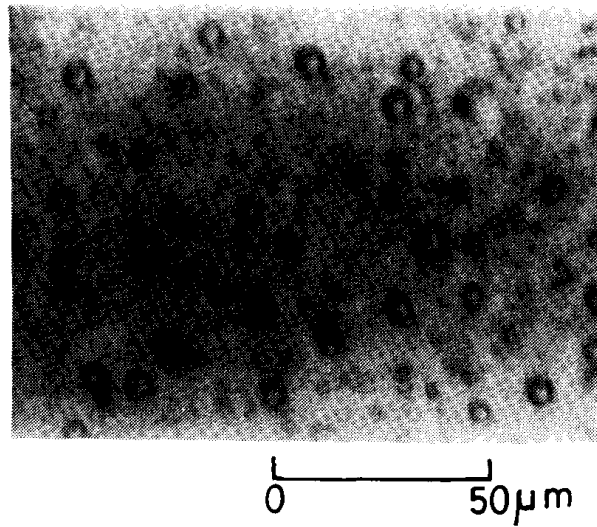

Figure 7.

Typical microphotograph of an aged sample, pressure: $21.95 \mathrm{kPa}, Q_{m}=4000 \mathrm{pC}$, time of aging: $290 \mathrm{~min}$.

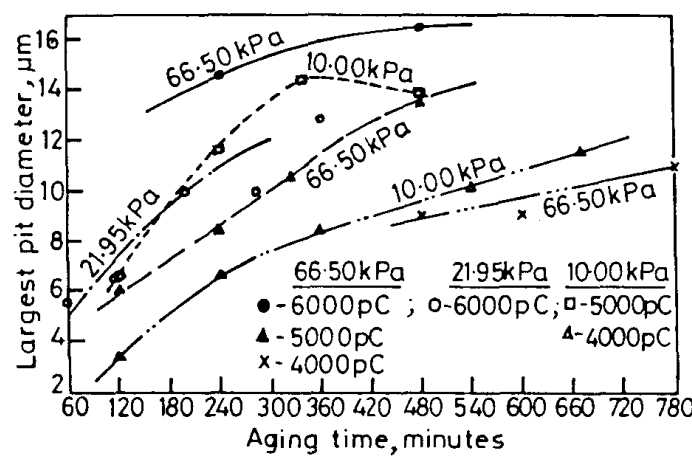

Figure 8.

Variation of pit diameter with aging time.

thickness of the film is $t$, after aging the remaining thickness is $t-r$. This remanent thickness is plotted against the measured breakdown voltage of the aged samples as shown in Figure 9. It is observed that these points lie close to the BDV thickness curve, showing that due to $\mathrm{PD}$, there is a reduction in the thickness of the films and that a good estimate of the erosion can be obtained by measuring the pit diameters from the microphotographs.

\section{CONCLUSIONS}

1. A short-term room temperature aging test to study the effect of PD on PP films is possible using uniform field electrodes and a suitable air gap.

2. Residual breakdown voltage can be considered as a criterion for PP film degradation as this property shows a systematic variation with discharge magnitude and aging time.

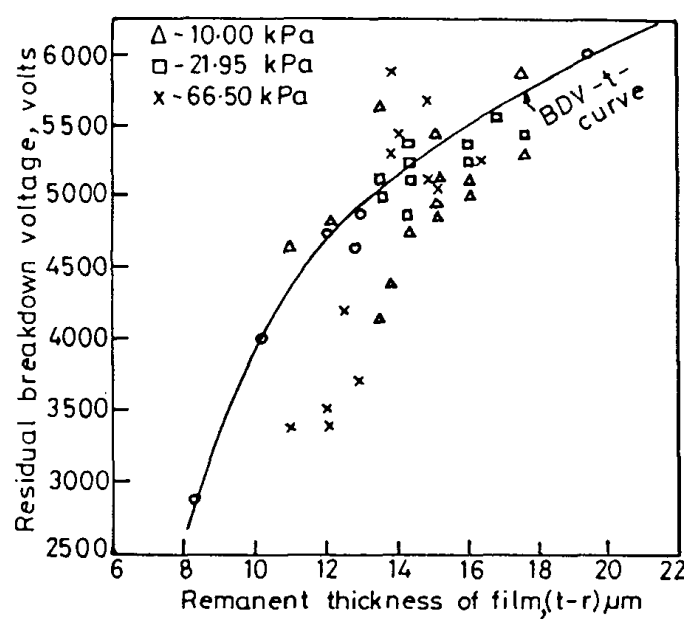

Figure 9.

Correlation between pit diameter and residual breakdown voltage.

3. The estimated lifetime using Equation (1) agrees well with the lifetime from the actual life tests.

4. For the same applied stress, the voltage endurance coefficient $n$ of PP film varies with initial maximum discharge magnitude.

5. The lifetime estimated under experimental conditions show no significant variation with pressure in the range of 10 to $66.50 \mathrm{kPa}$.

6. For the estimation of life under lower and practical discharge magnitudes, the equation $L=A Q_{m}^{B}$, seems to yield results close to expected values.

7. The total discharge magnitude/s shows a good correlation with the estimated lifetime, in the range of discharge magnitudes used.

8. Remanent thickness of the film (as calculated from the pit diameters) shows a good correlation with the residual breakdown voltages.

\section{ACKNOWLEDGMENTS}

THE authors thank the authorities of the Indian Institute of Science, Bangalore, India, for the facilities and the permission to publish this work. One of the authors (VK) thanks the authorities of M. S. Ramaiah Institute of Technology, Bangalore, India, for granting leave to pursue this work. 


\section{REFERENCES}

[1] T. Umemura, K. Abe, K. Akiyama and Y. Tanaka, "All Film Power Capacitor with Folded Electrode Foil", IEEE Trans. Power Delivery Vol. 2, pp. 182$187,1987$.

[2] G. A. Curtis, O. Nerf, K. Wenzel and D. Zanobetti, "The Behavior of Power Capacitors in Service Conditions Involving Overvoltages", Proc. CIGRE, Paris, France, paper 15-08, pp. 1-14, 1978.

[3] D. G. Shaw, S. W. Cichanowski and A. Yializis, "A Changing Capacitor Technology-failure Mechanisms and Design Innovations", IEEE Trans. Electr. Insul., Vol. 16, pp. 399-413, 1981.

[4] J. R. Laghari, "A Review of ac and Pulse Capacitor Technology", Applied Physics Communications, 6 (2 and 3), pp. 213-251, 1986.

[5] T. W. Dakin, H. M. Philofsky and W. C. Devins, "Effect of Electric Discharges on the Breakdown of Solid Insulation", AIEE Trans. Commun. and Electronics, Vol. 73, pp. 155-162, 1954.

[6] F. H. Kreuger, "Determination of the Internal Discharge Resistance of Dielectric Materials",IEEE Trans. Electr. Insul., Vol. 3, pp. 106-114, 1968.

[7] IS (Indian Standards): 2834-1986, Specification for Shunt Capacitors for Power Systems.
[8] BS (British Standards): 1650-1971, Specification for Capacitors for Connection to Power Frequency Systems.

[9] J. D. Cobine, Gaseous Conductors, Dover Publications NY, Chapter 8, 1958.

[10] L. Simoni, "A New Approach to the Voltage Endurance Test on Electrical Insulation", IEEE Trans. Electr. Insul., Vol. 8, pp. 76-86, 1973.

[11] V. Krishnan and R. S. Nema, "A Study on PD Degradation of PP Films", Proc. IEEE Int. Conference on Electrical Insulation and Dielectric Phenomena, Gaithersburg, Md, pp. 120-125, 1987.

[12] D. R. Augood, "Dielectric Aging, Overview and Comment", Proc. IEEE Int. Symp. on Electr. Insul., Philadelphia, Pa, pp. 17-21, 1978.

[13] S. Cesari, E. Serena, E. Sesto, E. Bertani, W. Mosca, V. Zanarini. D. Zanobetti, G. Madama, M. Marconcini and C. Stanghellini, "A Contribution to the Evaluation of Various Impregnating Fluids for Power Capacitors", Proc. CIGRE, Paris, France, Paper 1508 , pp. 1-16, 1980.

[14] G. Pattini and L. Simoni, "Electric Strength and Voltage Endurance of Some Insulating Polymers", Proc. IEEE Int. Symp. on Electr. Insul., Montreal, Canada, pp. 19-23, 1976.

This paper is based on a presentation given at the 1987 CEIDP, Gaithersburg, MD, 18-22 October 1987

Manuscript was received on $26 \mathrm{Jun} 1988$, in revised form 15 Jun 1989 . 